\title{
Citation and Narration as the Nexus of Kristeva's Theory of Intertextuality
}

\author{
Andrew Bula (Corresponding author) \\ Centre for Foundation \& Interdisciplinary Studies, Baze University, Abuja, Nigeria \\ Email: andrew.bula@bazeuniversity.edu.ng
}

Received: $14 / 10 / 2021$

Accepted: 16/01/2022

Published: 01/03/2022

Volume: 3 Issue: 2

How to cite this paper: Bula, A. (2022). Citation and Narration as the Nexus of Kristeva's Theory of Intertextuality. Journal of Critical Studies in Language and Literature, 3(2), 7-14

DOI: https://doi.org/10.46809/jcsll.v3i2.130

This work is licensed under the Creative Commons Attribution International License (CC BY 4.0).http://creativecommons.org/licenses/by/4.0/

\section{(c) (i)}

\section{Abstract}

The theory of intertextuality as formulated by French scholar, Julia Kristeva, is much too misunderstood in critical circles. In many instances, the line of thinking is that intertextuality is simply a matter of influence - that is, the influence of one author on another or of one text (book) or more on another book or other books, et cetera. This study, therefore, purposes to understand Kristeva's theory of intertextuality; and, what is more, to unearth the central meaning of the theory, and the role of culture in the discourses. As a consequence, the full range of the theory, enumerated under these headings: The Novel as an Utterance, the Symbol as Ideologeme, the Sign as Ideologeme, Text Production, Intertextuality: An Analysis of Utterances, are all duly taken into account in this reading. In the end, it is laid bare that indeed the meaning of intertextuality does not in the main reside in the general notion of influence associated with the theory, although influence is implicated in it in principle. Rather, it is uncovered that the thrust of intertextuality is really what Kristeva designates as citation and narration, citation being dialogue and therefore the speech act of the character and narration being writing and hence the speech act of the narrator in the text of the novel.

Keywords: Citation, Narration, Intertextuality, Influence, Culture, Speech act, Utterances

\section{Introduction}

The theory of intertextuality which Julia Kristeva (1980) introduced in her work, Semeiotike: recherches pour une Semanalyse and later translated as Desire in Language: A Semiotic Approach to Literature and Art, is a neologism which derives from Mikhail M. Bakhtin's own formulation of the theory of dialogism, "the idea that a text contains language from more than one 'world' " (Leitch, p.2166) that he extensively discussed in his "Discourse in the Novel" (1934-35). (Leitch, p.1186) Further, Kristeva (1980) notes herself that "Bakhtinian dialogism identifies writing as both subjectivity and communication, or better, as intertextuality" (p. 68). The generally held notion of the theory of intertextuality, however, hinges on influence, the influence of one author's book on another's; or, of more books on other books, and so on. But actually, the idea of influence can only be associated with the theory in principle. This is because in Kristeva's formulation, intertextuality is really the intersection of two texts within the novelistic text. These two texts, according to Kristeva, are citation and narration. The former entails 'dialogue' while the latter implies 'narration', and it is precisely the interaction of these two texts within the text of the novel that constitutes the core meaning of Kristeva's intertextuality. In accounting for the theory, therefore, its various dimensions are considered in this exploration. 


\section{The Novel as an Utterance}

Thus, in the second chapter of her work, Kristeva (1980) views the novel and therefore literature by means of her theory of intertextuality as an exchange object and as an utterance with various textual and operative components. A glimpse of this is encountered in the following:

The text is defined as a trans-linguistic apparatus that redistributes the order of language by relating communicative speech, which aims to inform directly, to different kinds of anterior or synchronic utterances. The text is therefore a productivity, and this means: first, that its relationship to the language in which it is situated is redistributive (destructive-constructive), and hence can be better approached through logical categories rather than linguistic ones; and second, that it is a permutation of texts, an intertextuality: in the space of a given text, several utterances, taken from other texts, intersect and neutralize one another. (Kristeva, 1980, p. 36)

Viewed from this linguistic event alone, the term "text" would be misunderstood as implying any written book. However, Kristeva (1980) does not allow for such an error as she writes, providing a context of what she means: "The novel, seen as a text, is a semiotic practice in which the synthesized patterns of several utterances can be read"(p. 37).With regards to evidence of Kristeva's notion of the novel as an exchange object, the following is proof: "the novel is already "literature"; that is a product of speech, a (discursive) object of exchange, with an owner (author), value, and consumer (the public, addressee)"(p. 57). In another quotation that follows, which forms part of the one set off the text above, there is yet evidence of the novel as an exchange object: "The text is defined as a trans-linguistic apparatus that redistributes the order of language by relating communicative speech, which aims to inform directly, to different kinds of anterior or synchronic utterances" (Kristeva, 1980, p. 36).Thus, this "trans-linguistic apparatus" (Kristeva, 1980, p. 36), is understood as a novel, an "object of exchange, with an owner (author)" (Kristeva, 1980, p. 57) "that redistributes the order of language by relating communicative speech, which aims to inform" (Kristeva, 1980, p. 36) the "consumer (the public, addressee)"(Kristeva, 1980, p. 57).

In accounting for Kristeva's perception of the novel as an utterance with various textual and operative constituents, the statement that "the novel, seen as a text, is a semiotic practice in which the synthesized patterns of several utterances can be read" (Kristeva, 1980, p. 37) proves here again helpful for attestation. In fact, Kristeva (1980) further outlines her approach to this question of the novel as an utterance in this fashion:

For me, the utterance specific to the novel is not a minimal sequence (a definitely set entity). It is an operation, a motion that links, and even more so, constitutes what might be called the arguments of the operation, which, in the study of a written text, are either words or word sequences (sentences, paragraphs) as sememes. Instead of analyzing entities (sememes in themselves), I shall study the function that incorporates them within the text. That function, a dependent variable, is determined along with the independent variables it links together; more simply put, there is univocal correspondence between words or word sequences. It is therefore clear that what I am proposing is an analysis that, while dealing with linguistic units (words, sentences, paragraphs), is of a translinguistic order. Speaking metaphorically, linguistic units (and especially semantic units) will serve only as springboards in establishing different kinds of novelistic utterances as functions. By bracketing the question of semantic sequences, one can bring out the logical practice organizing them, thus proceeding at a suprasegmental level. Novelistic utterances, as they pertain to this suprasegmental level, are linked up within the totality of novelistic production. By studying them as such, I shall establish a typology of these utterances and then proceed to investigate, as a second step, their origins outside of the novel. (p. 37)

It can be comprehended from the foregoing that Kristeva's semiotic praxis which investigates the novel as a composite of utterances is functional in its design. In fact, it can also be understood from the excerpt above that Kristeva considers the various modes of utterances bound up within the novel as functions which relate to a suprasegmental element. In her study of these utterances in a novel, therefore, Kristeva(1980) sets up a typology of them and further opens a probe into "their origins outside of the novel" (p. 37). Tracing the beginnings of novelistic utterances outside the novel inevitably leads to what Amechi Akwanya (2015), working farther east of the country, at the University of Nigeria, Nsukka, sees as

an approach to literature that is much older than formalism in which the language of the text corresponds to something outside language. This 'something' outside language must be the function that incorporates the linguistic elements into a text, giving them the structure of "what might be called the arguments of the operation'. It is this 'something' outside language, according to Kristeva, that the literary work is constituted to represent. (p. 267)

Accordingly, Kristeva (1980) isolates two structures of representation, namely: representation via the symbol and representation via the sign, each of which is established by a thing she terms its 'ideologeme' - that is, "the ideologeme of the sign" and "the ideologeme of the symbol" (p. 37).

\section{The Symbol as Ideologeme}

As she conceives it, the aeon of the semiotic praxis of the symbol dates back from the mid-thirteenth century to the fifteenth century, and mythical thought functioned within this symbolic era, having such literary genres as the epic and the 
folktale. The "semiotics of the symbol", to use Kristeva's phrasing, was interested in eliciting "universal transcendences" (Kristeva, 1980, p. 38) as "heroism", "courage", "nobility", "virtue" "fear", treason", et cetera, that are "unrepresentable and unknowable" (Kristeva, 1980, p. 38). This signifies that there is non-conformity between the "symbolized-symbolizer" (Kristeva, 1980, p. 38), or, between a named object and its name. In other words, one cannot represent nor can one know, say, courage; it can be identified by its action or when it is demonstrated and experienced, not by its designation. Similarly, in the study of the symbol two dimensions of its functions have been brought forth and characterized. They are the "vertical dimension" as well as the "horizontal dimension" (Kristeva, 1980, p. 38). In the function of the symbol which pertains to the "vertical dimension", the exemplified genus of "symbolized universals" otherwise known as "universal transcendences" (Kristeva, 1980, p. 38) is determined. On the other hand, in the "horizontal dimension" (Kristeva, 1980, p. 38) of the function of the symbol, the symbol's ideologeme, known also as its function, "is one of escaping paradox" (Kristeva, 1980, p. 38). That is to say, within the science of the "horizontal dimension" of "the ideologeme of the symbol", "the articulation of signifying units" (Kristeva, 1980, p. 38), say, virtue and vice, are not contradictory as they are two linguistic poles. In fact, as Kristeva (1980) puts it, "one could even say that the symbol is horizontally antiparadoxical: within its logic, two opposing units are exclusive.The contradiction, once it appears, immediately demands resolution. It is thus concealed, "resolved", and therefore put aside" (pp. 38-39).

\section{The Sign as Ideologeme}

However, from the thirteenth century to the fifteenth century "the ideologeme of the symbol" was questioned as a result of which although it almost stopped to exist, it assimilated into "the ideologeme of the sign" (Kristeva, 1980, p. 39). Appropriately, the symbol has parallel as well as dissimilar characteristics with the sign. The parity between the sign and the symbol was, on the one hand, "the fundamental characteristic of the symbol" tagged its "irreducibility of terms" (Kristeva, 1980 , p. 40). By implication, just as in "the ideologeme of the symbol" there is non-conformity between the "signifying units" (Kristeva, 1980, p. 38), so it is in "the ideologeme of the sign" (Kristeva, 1980, p. 37). Kristeva regards the organic attribute of the symbol, the "irreducibility of terms" (Kristeva, 1980, p. 40) which is itself the framework of the sign as a trio, namely: the referent, the signified, and the signifier. Conversely, the difference between the sign and the symbol lies in the sign's vertical and horizontal functions. For, whereas what follows is not obtainable in "the ideologeme of the symbol" (Kristeva, 1980, p. 37), within the vertical function of "the ideologeme of the sign" (Kristeva, 1980, p. 37), "the sign refers back to entities both of lesser scope and more concretized than those of the symbol. They are reified universals become objects in the strongest sense of the word" (p. 40). This means, as Akwanya (2015) puts it, "the sign's vertical function narrows the gap between the representer and represented. The latter are entities that are nearer to experience, and though they may incorporate the symbolic universals, the sign function consists in making them "immediately perceptible"' (Akwanya, 2015, p. 267).

In the horizontal function of "the ideologeme of the sign" (Kristeva, 1980, p. 37), the "signifying units" (Kristeva, 1980, p. 38) of the "sign's semiotic practice" (Kristeva, 1980, p. 40) are expressed as a "metonymical concatenation of deviations from the norm signifying a progressive creation of metaphors. Oppositional terms, always exclusive, are caught within a network of multiple and always possible deviations (surprises in narrative structures), giving the illusion of an open structure, impossible to finish, with an arbitrary ending" (Kristeva, 1980, p. 40). By this, it is meant that the "signifying units" (Kristeva, 1980, p. 38) remain expressed within themselves as antithetical dyads; however the narrative is patterned, thus bringing about the impression of a disclosed form that will not cease, with an ending that is arbitrary. In addition, the semiotic praxis of the sign first became visible during the Renaissance period in the adventure type of novel that is configured on the unforeseeable and upon surprise as reality.

Thus, as Akwanya (2015) explains, the horizontal function and the vertical function "may be brought into the analysis of modern fiction. Corresponding to the horizontal function is the thematic structure" (p. 269) whereas "the vertical function involves an analysis of the novel's object status, where we may examine its segmental and suprasegmental features"” (p. 269). These textual properties are here studied by means of Kristeva's conceptions of 'productivity' and 'intertextuality'.

\section{Text Production}

Kristeva (1980) theorizes, it has already been noted, that the novelistic text is "a semiotic practice in which the synthesized patterns of several utterances can be read" (p. 37). This entails that there are utterances within "the text of the novel" (Kristeva, 1980, p. 38), which constitutes its fabric. What, therefore, can be seen is that in the making of the novel, it is not only one dimension of thinking that is worked into the text. This is in part what comes across in a statement by Kristeva (1980) that:

The novel has a double semiotic status: it is a linguistic (narrative) phenomenon as well as a discursive circuit (letter, literature). The fact that it is a narrative is but one aspect - an anterior one - of this particularity: it is "literature." That is the difference characterizing the novel in relation to narrative: the novel is already "literature"; that is, a product of speech, a (discursive) object of exchange with an owner (author), value, and consumer (the public, addressee). The narrative's conclusion coincides with the conclusion of one loop's trajectory. The novel's finitude, however, does not stop at this conclusion. An instance of speech, often in the 
form of an epilogue, occurs at the end to slow down the narration and to demonstrate that one is indeed dealing with a verbal construction under the control of a subject who speaks. The narrative is presented as a story, the novel as a discourse (independent of the fact that the author - more or less consciously - recognizes it as such). In this, it constitutes...speech. (p. 57)

The novel, therefore, has depth, and classed by Kristeva as a sub-type of narrative, with the specific feature of being literature. In fact, according to Kristeva (1980), it is "a verbal construction under the control of a subject who speaks" (p. 57). Similarly, "as a discursive circuit" (Kristeva, 1980, p. 57), Kristeva(1980) sees the novel as "a product of speech, a (discursive) object of exchange" (p. 57) whereby the author relays his or her speech which takes on the form of a narrative intended for the reader, who in turn absorbs it. Hence, in the words of Akwanya (2015), "Kristeva's theory of literature is a form of speech-act theory" (p. 269). This is evident in an articulation that "the novel...is a semiotic practice in which the synthesized patterns of several utterances can be read" (Kristeva, 1980, p. 37). Thus, Kristeva posits that there are two functions which blend these utterances within the textual ambience of the novel, and they are: the suprasegmental function and the intertextual function. Accordingly, there are two forms of dissections. This can be witnessed where Kristeva (1980) explains:

Two kinds of analyses, sometimes difficult to distinguish from each other, make it possible to isolate the ideologeme of the sign in the novel: first, a suprasegmental analysis of the utterances contained within the novel's framework will reveal it as a bounded text(with its initial programming, its arbitrary ending, its dyadic figuration, its deviations and their concatenation): second, an intertextual analysis of these utterances will reveal the relationship between writing and speech in the text of the novel. (p. 38)

Thus, a suprasegmental analysis is oriented towards accounting for the modes of utterance within the framework of the novelistic text. According to Kristeva (1980), the first utterance is to be found in the relations between the author and the reader, between the "(exchange object)/addressee" (p. 42), as she puts it, and it is this that engenders "the first loop" (p. 42) utterance.

Kristeva (1980) further explains that the "second loop" (p. 42) exists "at the thematic level" (p. 42), where there is an interaction between two opposites otherwise known as "thematic loops" (p. 48), like "life-death, love-hate, fidelity-treason" (p. 48) which "frames the novel" (p. 48). As Akwanya (2015) elucidates, in which is contained overt and covert borrowings from Kristeva:

Every novel progresses by oscillating between the poles, and continues as long as the disjunction is sustained. This is the source of what is frequently referred to in the criticism of modern novels as the open structure, and it is this that ensures that the ending is quite arbitrary. This ending is achieved by the choice of one of the terms against the other, and is sometimes triggered off by the appearance of a figure capable of being seen in one light and equally in the other, figures 'that have a double destination'. (p. 272)

Appropriately, the outlined model of figures, "utterances that can be doubly interpreted or have double destinations" (Kristeva, 1980, p. 43), are: "ruses, treason, foreigners" and "androgynes" (p. 43).

\section{Intertextuality: An Analysis of Utterances}

In undertaking an intertextual analysis of utterances, consideration should be first given to what the term 'intertextuality' entails. As a consequence, it is worthy of note that many of the usages of this term are not in consonance with its original sense. This much is decried by Leon S. Roudiez (1980) who, in his introduction to Kristeva's work, sets forth the view that Kristeva's theoretical matrix "has generally been misunderstood. It has nothing to do with matters of influence by one writer upon another, or with the sources of a literary work" (p. 15). Indeed, this is what comes across in the thinking exercised by Abrams and Harpham (2012):

The term intertextuality... is used to signify the multiple ways in which any one literary text is in fact made up of other texts, by means of its open or covert citations and allusions, its repetitions and transformations of the formal and substantive features of earlier texts, or simply its unavoidable participation in the common stock of linguistic and literary conventions and procedures that are "always-already" in place and constitute the discourses into which we are born. In Kristeva's formulation, accordingly, any text is in fact an "intertext"- the site of an intersection of numberless other texts, and existing only through its relations to other texts. (p. 401)

While it is not doubted that, in principle, uncovering Kristeva's schema does implicate the question of a network of singular texts, Abrams and Harpham have nevertheless missed the nexus of the theory. In fact, their find on the matter ties in with the perspective of Mary Klages (2013) that:

Intertextuality means the interactions of texts. Coined by Julia Kristeva in reference to Mikhail Bakhtin's ideas of heteroglossia, intertextuality posits that a text (literary or non-literary) never exists in isolation. Rather, all texts are made up of references to or quotations from other texts, and are always in conversation with other texts. Intertextuality is not restricted to the idea of one author being influenced or informed by another author, but rather encompasses the idea that each text is engaged with preceding texts. (p. 44)

Here, too, the crux of the theory is missed as this viewpoint is literal and therefore misleading. For, whereas there is in this viewpoint the suggestion that intertextuality transcends 'influence'; "it has nothing to do with matters of influence" 
(Roudiez, 1980, p. 15) to begin with. Besides, in Klages' characterization of the concept, the nature of this transcendence of influence is not taken up.

In the work of Sylvan Barnett et al (2001), a parallel can also be drawn. For Barnett et al (2001) have described intertextuality as,

all works show the influence of other works. If an author writes (say) a short story, no matter how original she thinks she is, she inevitably brings to her own story a knowledge of other stories - for example, a conception of what a short story is, and, speaking more generally, an idea of what a story (long or short, written or oral) is. In opposition to formalist critics, who see a literary work as an independent whole containing a fixed meaning, some contemporary critics emphasize the work's intertextuality - that is, its connections with a vast context of writings and indeed of all aspects of culture, and in part depending also on what the reader brings to the work. Because different readers bring different things, meaning is thus ever-changing. In this view, then, no text is self-sufficient, and no writer fully controls the meaning of the text. Because we are talking about connections of which the writer is unaware, and because "meaning" is in part the creation of the reader, the author is by no means an authority. Thus the critic should see a novel (for instance) in connection not only with other novels, past and present, but also in connection with other kinds of narratives, such as TV dramas and films, even though the author of the book lived before the age of film and TV. (p. 1768)

Although this perspective matches the others already examined here, all of which do not tally with the nucleus of Kristeva's theory, it does mention the fact that intertextuality has also to do with a text's association with culture, something which is not contained in the other viewpoints considered. Too, going by the primacy of the signification of the theory, there cannot be intertextual cases in films and TV dramas as Barnett et al aver.

But, again, the theory is not about influence as Ahmadian and Yazdani (2013) believe it to be when they write in their article that "intertextuality is, generally, defined as the relating elements of the previous texts that influence and gather to construct (a part of) the present text. According to Kristeva (1980), no text is original and is made by itself isolated from those existing before it; such a text is influenced by the texts and textual elements relating to it" (155). However, should it not have been useful, if Ahmadian and co indicated in what portion of Kristeva's work the latter part of the preceding paraphrase/quotation can be found? But this is not made manifest, despite that they signal a quotation from the source itself with the use of "according to Kristeva (1980)"! Besides, in Kristeva, it is clear that intertextuality as a theory is situated within the context of the "novel", not "short stories"; strictly, Kristeva theorizes about intertextuality in relation to the novel! Hence, it is startling that Zengin (2016) sets down in his article, that "it was Kristeva who first saw no discrimination between the literary and non-literary texts. ... Any work of art, for Kristeva, is an intertext which interacts with the other texts..." (300). In point of fact, Shakib (2013) incorrectly toes a similar line, reasoning that there are two major types of intertextuality, namely: "ekphrasis and iconotext" (n.p) and that the concept exists in film, newspaper, and computer screens. And yet, even though the theoretical basis of his paper rests on several accounts of the concept, it is altogether intelligible in the article that Shakib rightly credits Kristeva for formulating the term "intertextuality"! And so, it is, again, surprising that Kristeva's intertextuality could be said to have something to do with film, computer screens, and newspapers. But Shakib does not engage in this misconception all by himself. In an article, Zoonen (2017) is much in sync with Shakib's thinking when he writes that:

Intertextuality is a term to indicate that all texts, whether written or spoken, whether formal or informal, whether artistic or mundane, are in some ways related to each other. It is a particularly apt term to understand current media culture, with its still increasing abundance of images, sounds, characters and stories. The term comes from literary studies but was taken up by critical media scholars in the 1970s and 80s to examine particular popular genres. Currently, the term has found some currency among media psychologists as well. In this entry, the provenance of the concept of intertextuality is described, using James Bond and Lady Gaga as iconic examples. (p.1)

It is obvious in this quotation and in the entirety of the article that intertextuality as discussed by Zoonen is not properly grounded in literary criticism or in Kristeva! Hence, the article lacks depth and grasp of the theory, which is, in fact, why in it the 'dimensions' of the concept too are grossly misinterpreted as being 'differences of texts'. In their article, it is apparent that Manjavacas et al (2020) also follow the erroneous, proliferating trend of seeing intertextuality as being about influence. A case in point is where it is written thus:

Originally proposed by post-structuralist literary theorist, Julia Kristeva..., intertextuality models literature as an intricate network of textual nodes that are interconnected by the 'intertexts' that they share. Texts can refer to one another, for instance, through the literal integration of quotes from other works or through the inclusion of more subtle allusions to other texts. (Manjavacas, 2020, p.77)

What is expressed here is, again, part of the meaning of intertexuality. But it is not its integral meaning. For, what the above quotation entails boils down to influence, something to which Prandoni (2012) is agreeable when discussing intertextuality in the following: "Every individual text is generated at the intersection of a potentially infinite number of previous texts and bears in it the echoes of a plurality of codes, systems, conventions - and not just linguistic ones." (p. 273) But there are yet other deficient viewpoints to the theory.

The French scholar, Roland Barthes, for his part regards intertextuality as "the text-between of another text" (qtd. in Akwanya p. 272) of which as Akwanya (2015) lays out the verdict: 
Barthes rather takes the idea quite literally... and yet the elaboration with which he follows this shows how little intentionality has to do with it: 'the citations which go to make up a text are anonymous, untraceable, and yet already read: they are quotations without quotation marks'... Where this prior textual experience takes place, Barthes explains, is in the history of language as a written form: for 'writing...remains full of the recollection of previous usage... [and] words have a second-order memory which mysteriously persists in the midst of new meanings'. (pp. 272-73)

This literalness of contemplating the matter is also the stance of one characterization of intertextuality. "The relationship between pieces of writing" (Soanes and Hawker, 2008, p. 532), it says. In this inquiry, therefore, Kristeva is followed in order to unravel the nuances of meaning of her theory of intertextuality as well as the cardinal meaning of the theoretical construct.

Hence, for Kristeva (1980), part of the meaning of intertextuality is situated in culture, the fact of which underlies her remark that: "The concept of text as ideologeme determines the very procedure of a semiotics that, by studying the text as intertextuality, considers it as such within (the text of) society and history" (p. 37). For the terms "society" and "history" translate to culture. Expressing the same notion elsewhere within her work, Kristeva(1980) is explicit: "One of the problems for semiotics is...to define the specificity of different textual arrangements by placing them within the general text (culture) of which they are part and which is in turn, part of them" (p. 36). Thus, for Kristeva, as seen here, there is interweaving between a literary text and the general cultural text.

By inference, another meaning of intertextuality can be derived from the foregoing. Which is to say that a literary text owes something to the text of culture itself; therefore, it is part of culture and culture itself, by virtue of its own materials being involved in the production of a literary text, is then part of a literary text. In fact, in the words of Akwanya (2015): "This intersection is what gives the text significance as an agent of the cultural ideology. Hence it is an ideologeme". (p. 272) Further, as Akwanya (2015) explains: "This intersecting of the narrative with the social matrix, the texts of the rural and cosmopolitan cultures, and with other semiotic practices (literary texts of the tradition), is also studied under intertextuality" (p. 275).

However, the cardinal meaning of intertextuality resides in the modes of speech assembled in the text of the novel. This is what Kristeva (1980) means when in chapter three of her work, she characterizes intertextuality as "any text" (p. 66) "constructed as a mosaic of quotations; any text is the absorption and transformation of another" (p. 66). But this is not to be taken literally, for Akwanya (2015) explains that intertextuality "is a quality that pertains to the very form of narrative" (p. 273). According to Roudiez (1980), intertextuality does "involve the components of a textual system such as the novel" (p. 15). Correspondingly, Roudiez (1980) articulates the view that in another work by Kristeva, La Revolution du langage poetique, translated as Revolution in Poetic Language, intertextuality is described as "the transposition of one or more systems of signs into another, accompanied by a new articulation of the enunciative and denotative position" (p. 15).

The "systems of signs" (Roudiez, 1980, p. 15) mentioned here incorporates linguistic units appropriate to a particular object of knowledge. Implicit in the foregoing is the facts that the "systems of signs" (Roudiez, 1980, p. 15) include two types of utterances that Kristeva theorizes are contained in the novelistic text. Note that these novelistic utterances are not to be taken literally, for Kristeva (1980) identifies them to be 'narration and citation' in the following: "I have examined elsewhere the topology of speech acts in the text of the novel. It unveils the writer as principal actor in the speech play that ensues and, at the same time, binds together two modes of the novelistic utterance, narration and citation, into the single speech of he who is both subject of the book (author) and object of the spectacle (actor)" (p. 45). This entails that narration is the speech act of the author whereas citation is the speech act of the character in the text of the novel, as it is the speech of the "object of the spectacle (actor)" (Kristeva, 1980, p. 45) and as it is the "speech attributed to an other" (Kristeva, 1980, p. 45) respectively. Hence, for Kristeva, there is no distinction between the author and the narrator; the two are the same.

Accordingly, the 'orientations', to use Kristeva's term, of both the narrator and the actor or character, are 'referential' and 'inferential' respectively. A statement within which this is attested to reads as follows: "the modality of novelistic enunciation is inferential: it is a process within which the subject of the novelistic utterance affirms a sequence, as conclusion of the inference, based on other sequences (reference - hence narrative, or textual - hence citational), which are the premises of the inference and, as such, considered to be true" (Kristeva, 1980, p. 45). Citations, then, are "textual premises" (Kristeva, 1980, p. 46) on a broad-based spectrum which "tie together" (Kristeva, 1980, p. 46) in the text of the novel via what Kristeva (1980) tags "inferential agents" (p. 46). The "inferential agents" (p. 46), Kristeva (1980) notes, are "empty words whose functions are both junctive and translative. As junctive, they tie together (totalize) two minimal utterances (narrative and citational) within the global, novelistic utterance" (p. 45). Thus, in this report filed by Kristeva, it can be deduced that Kristeva (1980) views the novel as a whole to be an utterance within which are binary "minimal utterances" (p. 45) known as "narration and citation" (p. 45).

On the other hand, Kristeva (1980) further reflects, "as translative" (p. 46), "they transfer an utterance from one textual space (vocal discourse) into another (the book), changing its ideologeme. They are thus intranuclear (for example), the transposition of hawkers' cries and blazons into a written text)" (p. 46). Taking one's cue from Kristeva's and Akwanya's exemplification of the matter in their critical works; consider, for instance, a sequence taken from Achebe's novel, Arrow of God, in which can be seen the grafting of 'narration' onto 'citation' by means of the 'junctive' function. Writes Achebe (1986): "It was five years since Ezeulu promised the white man that he would send one of his sons to church" (p. 45). In the first clause, the phrase: "It was five years since" is narrative. In the second, a junctive is introduced by the presence of 
'promised' which enacts the function of connecting narration as well as the character's speech. In another novel by Achebe (2008), Things Fall Apart, the following is also taken which is an illustration of the transference of the vocal text into the text of the book, since for Kristeva the vocal is text as is the written: "Nnaayi', he said" (p. 15); 'said' is translative as it transfers the "textual premise" (Kristeva, 1980, p. 45) in the form of the character's speech 'Nnaayi' from the space of the vocal into the space of the book. Hence, "they establish a similitude, a resemblance, an equalization of two different discourses" (Kristeva, 1980, p. 46).Thus, as Akwanya (2015) sums it up: "This appearance of the narrator's speech act and that of the character together, the appearance of the spoken form in the space of the written, of a quoted text inside the space of a new formation, is the core meaning of Kristeva's notion of intertextuality" (p. 274). Indeed, this is the outline of Kristeva's thesis, and it is this that is the cardinal meaning of intertextuality.

\section{Conclusion}

The prime meaning of Kristeva's theory of intertextuality is citation and narration, these being dialogue on the one hand and writing on the other within the textual ambience of the novel. So then, it is essentially the intersection of these two texts in the context of the novel that comprise the main signification of the theory. These processes at work in the novel are understood as being facilitated by the "inferential agents", which are "empty words" with junctive and translative functions. In their junctive operation, the inferential agents perform the function of grafting narration onto citation in the novelistic text as a whole, whereas in their translative operation they effect the transference of an utterance from one textual medium (the oral) into another (the written).

Influence, nonetheless, is a quality that pertains to intertextuality, but only in principle. By contrast, the ideologeme of the symbol and the ideologeme of the sign are actually two systems of representation born of an approach to literature far back in time which explains that a literary work is constructed to represent what Akwanya appropriately views as something away from language. Since Kristeva's approach to literature is functional in its design, the "ideologeme" is the function that sets up both representation by the symbol and representation by the sign in a literary text, which translates to the fact that the "ideologeme" is what is also known as "the represented" as well as "things outside of language". In the ideologeme of the sign the space between the referent and the signified is made small by the sign's vertical function, thereby making the "symbolized universals" discernible at once. Within the horizontal function of "the ideologeme of the sign", however, the "signifying units" remain demonstrated in themselves as oppositional dyads, no matter how the narrative is structured; thereby occasioning the sense of an unlocked form that will not come to an end, with a conclusion that is arbitrary.

Under "Text Production", Kristeva, considering the novel as a site with several novelistic utterances, has isolated the first "utterance", otherwise known as 'figures', to be communication between the text and the reader. Kristeva's theory, therefore, is communicative by its design. The second utterance occurs at the level of theme, where there is interplay of antithetical dyads as love and hate, life and death. This disjunction is found in every novel, notes Akwanya, and it is broken off by the choice of one opposing dyad over the other, thus rendering the novel's closure arbitrary. Sometimes, however, it is the presence of a figure of "double destinations" as "foreigners" or "androgynes" that sets this ending in motion.

\section{References}

Abrams, M.H, and Harpham, G. G. (2012).A glossary of literary terms (10 ${ }^{\text {th }}$ ed.). U.S.A Wadsworth. Achebe, C. (2008). Things fall apart. England, Britain: Pearson.

---.Arrow of god (1986). England, Britain: Heinemann.

Ahmadian, M., and Hooshang, Y. (2013).A study of the effects of intertextuality awareness on reading literary texts: the case of short stories. Retrieved from //www.semanticscholar.org/paper/A-Study-of-the-Effects-of-IntertextualityAwareness-Ahmadian-Yazdani c1b025

Akwanya, A.N. (2015). Semantics and discourse: Theories of meaning and textual analysis. Enugu, Nigeria: U of Nigeria P. Barnet, S. et al. (2001).An introduction to literature: fiction, poetry, drama (twelfth edition). New York, U.S.A: Longman. Klages, M. (2013).Key terms in literary theory. London, Britain: Bloomsbury.

Kristeva, J. (1980). Desire in language: A semiotic approach to literature and art. Oxford, Britain: Basil Blackwell.

Leitch, V. B. (2001). The norton anthology of theory and criticism. New York, U.S.A: W.W. Norton \& Company.

Manjavacasa E, Folgert, K. and Mike, K. (2020).A statistical foray into contextual aspects of intertextuality. Retrieved from http://ceur-ws.org/Vol-2723/long28.pdf

Prandoni, M. (2012).Intertextuality - gysbreght van aemstel (1637).Retrieved from https://brill.com/view/book/edcoll/9789004218833/B9789004218833-s015.xml

Roudiez, L. S. (1980). Introduction. Desire in language: A semiotic approach to literature and art. Oxford, Britain: Basil Blackwell.

Shakib, M. K. (2013). Inevitability of arts from inter-textuality. Retrieved from https://academicjournals.org /journal/IJEL/article-abstract/EFE67D43571

Soanes, C., and Hawker, S. (2008). Compact oxford english dictionary of current English (3rd ed. Revised). Oxford, Britain: Oxford UP. 
Zengin, M. (2016).An introduction to intertextuality as a literary theory: definitions, axioms andthe originators.Retrievedfromhttps://www.researchgate.net/publication/312035152_An_Introduction_to Intertextuality_as_a_Li terary Theory Definitions Axioms and the Originators

Zoonen, L. V. (2017). Intertextuality. Retrieved from https://www.researchgate.net/publication/313405629_Intertextuality 